\author{
Г. А. Мольков \\ Институт лингвистических исследований РАН \\ (Санкт-Петербург, Россия) \\ georgiymolkov@gmail.com
}

\title{
ЗАИМСТВОВАНИЯ В ТРАКТАТАХ А.П. ГАННИБАЛА ПО ГЕОМЕТРИИ И ФОРТИФИКАЦИИ (1725-1726 ГГ.): К ИСТОРИИ НЕИЗМЕНЯЕМЫХ ПРИЛАГАТЕЛЬНЫХ В РУССКОМ ЯЗЫКЕ
}

Яркой особенностью трактатов А. П. Ганнибала (1696-1781) является большое количество галлицизмов в языке автора — в первую очередь, в сфере терминологической лексики. Значительную часть этих заимствований составляют имена прилагательные, основная часть которых используется в неизменяемом виде. В статье рассматривается ряд особенностей функционирования неизменяемых прилагательных у Ганнибала: наличие в некоторых случаях русских склоняемых эквивалентов к ним, попытки морфологической адаптации отдельных лексем, случаи омонимии неизменяемых адъективов и субстантивов. Автор предпочитает морфологически неадаптированные адъективы их русским эквивалентам и образованию склоняемых прилагательных с заимствованным корнем; по-видимому, эта особенность связана с терминологическим характером их употребления. В сфере фортификации заимствованные термины представлены значительно шире, чем в трактате по геометрии, т. к. базовая геометрическая терминология уже имела традицию использования в русском языке в связи с широким распространением геометрических сведений в России в допетровское время.

Язык трактатов А.П. Ганнибала является интересным свидетельством того, что потенциально русский язык был готов к появлению категории неизменяемых прилагательных уже в первой трети XVIII в. Эта возможность не была реализована, по-видимому, в связи с изменением языкового вкуса во второй половине XVIII в. и только в ХХ в. развилась в русском языке.

Ключевые слова: неизменяемые прилагательные, язык Петровской эпохи, А. П. Ганнибал, терминология фортификации, терминология геометрии.

Появление в русском языке неизменяемых прилагательных происходит на позднем этапе, уже в период существования литературного языка нового типа. Однако в научной литературе, непосредственно посвящённой описанию этой категории, 
время её появления в языке и ранний период существования описываются очень огрублённо и неточно. В работах последних десятилетий на этот счёт можно встретить следующие суждения.

Д. В. Бондаревский в диссертации, посвящённой категории неизменяемых прилагательных в русском языке, отмечает: «Появление в русском литературном языке заимствованных неизменяемых прилагательных относится к концу 18 - началу 19 вв.» [Бондаревский 2000: 10]. В статье 2016 г. А. А. Горбов даёт ту же хронологическую привязку: «В исследованиях, посвященных проблемам описания неизменяемых элементов, выступающих в роли определения к существительным, указывается, что заимствованные единицы такого типа появились в русском языке на рубеже XVIII-XIX вв., но их список включал в себя лишь несколько цветообозначений» [Горбов 2016: 134].

При этом в указанных работах отмечается, что в активную фазу развитие этой категории вошло только в XX веке. Сам термин «неизменяемые прилагательные» был введён А.А. Шахматовым, впервые теоретически рассмотревшим этот феномен, а в сфере лексикографии эта категория впервые выделяется с помощью отдельной пометы в словаре под ред. Д. Н. Ушакова; во второй половине века категория неизменяемых прилагательных начинает регулярно фиксироваться и описываться русскими грамматиками (начиная с академической грамматики 1970 г.) и словарями (см. обзоры в [Бондаревский 2000: 10-12, 97-100; Бранднер 2001: 108]).

Возможно, названные исследования ориентируются в своей обзорно-исторической части на работы предшественников, опубликованные полвека назад. В частности, А.И. Молотков в 1960 г. в журнале «Вопросы языкознания» высказал точку зрения об отсутствии неизменяемых прилагательных в русском языке как особой морфологической категории. Говоря о проникновении первых подобных форм в русский язык, он пишет, что «время появления “неизменяемых прилагательных” в русском языке почти датировано: вполне достоверно здесь можно говорить о XIX и ХХ вв.» [Молотков 1960: 69].

Между тем, в процессе подготовки и издания «Словаря русского языка XVIII века» и параллельно проводимых коллективом исследований языка этого периода были описаны и лексикографически обработаны факты, показывающие неправомерность описанной оценки начального этапа функционирования неизменяемых прилагательных в русском языке. Важные сведения по этому вопросу приводятся в исследовании о заимствованиях в русском языке XVIII века: «Контексты XVIII в. демонстрируют весьма широкое употребление неадаптированных форм прилагательных в зап.-европ. или классическом (преимущественно лат.) оформлении, в функции атрибутивной и в качестве предиката. Таковы формы женероз, капабель, комод, магнифик, комплет, конфини, аттик, диферент, десперат, малконтент, офенсив, директ, масив, позитив, фурьез, комплезан, пропре, акииденталис, ориенталис, диагоналис, целестис, арктикус, солидус, меридионалис, милитарис, навалис, изивилис и т.п.» [Биржакова и др. 1972: 237]. Часть подобных прилагательных представлена в СлРЯ XVIII с пометой неизм. прил. / неизм., ср.: 
ДИАГОНАЛИС 1709, неизм., прил. [СлРЯ ХVIII 6: 123]; КАПАБЕЛЬ 1727 (копабил 1711), неизм. прил. [Там же, 9: 240] и др.

При полном отсутствии в специальных работах по истории неизменяемых прилагательных материалов XVIII в. остаётся актуальным суждение авторов процитированной выше коллективной монографии о перспективности исследований на этом материале: «Русские словообразовательные аффиксы, сочетающиеся с основами иноязычных прилагательных, их взаимные отношения в словообразовательной системе XVIII в., новые суффиксы и новые структурно-семантические типы как результат освоения иноязычных прилагательных должны составить предмет специального исследования» [Биржакова и др. 1972: 237, сноска 80].

В описанной ситуации большой интерес представляют неопубликованные рукописные трактаты по геометрии и фортификации (далее - Г и Ф) А. П. Ганнибала, ныне хранящиеся в основном собрании рукописного отдела БАН (СПб.) под общим шифром 17.14.4. Как указывает автор в предисловии, посвящённом Екатерине I, его пособия представляют собой переведённую с французского компи-

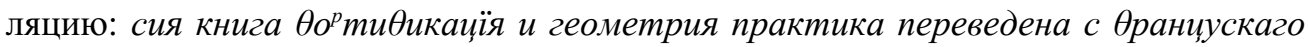
диалекта на ро ссиіски вы

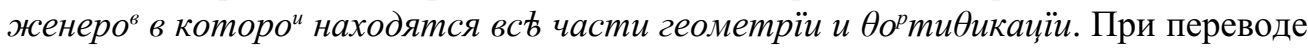
А.П. Ганнибал активно заимствовал терминологию оригиналов [Мольков 2018], в том числе и атрибутивную лексику. Как показывает сплошная выборка материала по заимствованным прилагательным, эта лексика в сочинениях Ганнибала очень активна и отличается низкой степенью морфологической адаптированности, что даёт возможность сделать подробные наблюдения, существенные для реконструкции ранней истории неизменяемых форм прилагательных в русском языке Нового времени.

Два рассматриваемых трактата отличаются разной степенью употребительности заимствованных атрибутивов. В геометрическом томе их используется ограниченное количество (не больше 10), и большинство из них известны в XVIII в. и из других сочинений и зафиксированы в СлРЯ XVIII. Среди них, например, термин исос(с)ель 'равнобедренный' - Триангуль исоссель. которо им иеть два бока равны [Г, с. 6]; триангу" исосе ${ }^{n}[\Gamma$, с. 32]; .3. бока, и три угла, то принадлежитъ бокамъ триангулов, экилетераля, изоселя, скалена. [Г, с. 97]; этот термин Ганнибал продолжает использовать и в томе по фортификации: для нахождения раїона $A P$. здъла" в триангуле исо сель $A P B$, в которо познаешъ угль басъ $A B$ 120 саженъ, таки" образо [Ф, с. 22]; СлРЯ XVIII приводит следующие контексты: Из дву даных прямых линеи здълать треуголник изосиелес, имъющеи в себъ двъ стороны равныля. Геом. 170998. Треугольник изосиель. ЛВ ${ }^{1}$ II 227 [СлРЯ XVIII 9: 59]. При этом, по данным Словаря, слово изосиель является несклоняемым заимствованием, в то время как примеры из сочинений Ганнибала показывают его способность видоизменяться по именному склонению (см. подробнее ниже). Аналогичным образом представлены и антонимичные прилагательные эгю 'острый' и обтю 'тупой'. В трактатах Ганнибала они используются часто: Еще углы $\mathrm{pa}^{3} \mathrm{de-}$ ляютиа на .3. части сиесть прямои, эгю, \{или острой $\}$ обтю, $\{$ или тупой $\}$ [Г, с. 3]; 


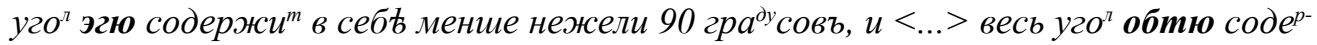
жить болше нежели .90. гра ${ }^{\text {ду совъ [Г, с. 6]; сей } \theta л а н к ъ ~ E F . ~<\ldots>~ д ъ л а е ~}{ }^{m}$ с куртино $E F$. уго $\boldsymbol{o}^{\boldsymbol{\sigma}} \boldsymbol{m ю}\left\{m y n o^{u}\right\}$ [Ф, с. 3] и мн. др. Слово обтю (в латинизированном облике обтюс) зафиксировано в СлРЯ XVIII в сочинении С. Мордвинова 1748 г.: Угол обтюс или тупой, которой болше прямова угла. Кн. навиг. I 9; в том же источнике используется, по данным КС XVIII, и антоним: Угол экгю или острой, которой менше прямово угла. Кн. навиг. I 8. Прилагательное облик 'косой, не прямой' также используется Ганнибалом в обоих трактатах — И ежели та же линея обликъ дву" плана ${ }^{\mu}$, то буде присмь обликъ ${ }^{*}<{ }^{*}$ пклонно ${ }^{u}>$ [Г, с. 11]; а ежели вмьсто параллелограма пропозують здълать параллелограмъ об ликъ \{или наклонно $\}$ на линеи .EF. надобно протянут линею ЕG. чтоб дълала съ ЕF. одинъ уго $[\Gamma$, с. 34]; Өланкъ обли-

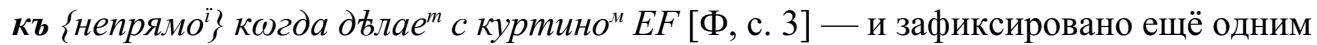
примером в том же сочинении С. Мордвинова: Линея облик или склонная. Кн. навиг. I 6 [СлРЯ XVIII 15: 259].

Такая относительно малая активность заимствований в сфере собственно геометрической терминологии в рассматриваемых текстах, по-видимому, связана с тем, что её развитие было поддержано широким распространением геометрических сведений в России в допетровское время - через руководства по землемерию, книги по астрономии и географии, военному делу [Кутина 1964: 31-32]. В связи с этим в наименовании базовых геометрических понятий Ганнибал пользовался по преимуществу сложившейся системой оригинальных русских терминов (или более ранних заимствований).

В сочинении по фортификации таких заимствований из французского становится на порядок больше. Этот обильный материал оказывается достаточно разнородным по степени адаптации, которая выражается в наличии / отсутствии форм словоизменения, в устойчивости атрибутивной позиции этих слов, а также в использовании для части вводимых терминов дублирующих русских соответствий. В полном тексте трактата было замечено около 70 лексем, которые можно отнести к обозначенной категории; приведём их с французскими соответствиями ${ }^{1}$ : абаскюль (в тексте - абанюль, описка вместо à bascule «откидной»), авантаж (avantage), антаналь (en tenaille), антере / энтерре (enterré), анфиле (enfilé), асичие (à scie), атребюше (à trébuchet), атюэль / атюгль (à étoile), афлеш (à flèches), бас (bas), вид (vide), виф (vif), де апрош (de approches), д’анфилад (d'enfilade), де армее (de armée), де дефанс (de défense), де куртин (de courtine), де реверс (de revers), де фрон (de front), де ла каземат (de la casemate), де ла транше (de la tranchée), дю кордон (du cordon), дю фланк (du flanc), деминюе (diminué), deтаме (détache), дефанс (défense), дефансив / -иф (défensive), диформ (difforme), дорман (dormant), дрои (droit), изоле (isolé), интериор / энтериор (intérieur), иррегуляре (irrégulier), кавалиер (cavalier), каре (carré), крозе (croisé), крюкс (сrеux), куверт (couvert), купе (coupé), курб (courbe), мажистрал (magistral), микст (mixte), милитер (militaire), морт (mort), облик (oblique), офансив (offensif), плат / плато / пла (plat), плен

\footnotetext{
1 Французские примеры приводятся по словарю [ФРЛ].
} 
(plein), пролонже (prolongé), разант (rasant), рантран / -нт (rentrant), ранфоce / ренфорсе (renforcé), ревет /-тю (revétu), реветемент (revétement), регуляре (régulier), ретире (retiré), ретранше (retranché), ройал (royal), ронд (rond), сеилян / -нт / селиант / селянт / саилянт (saillant), секонд (second), специал (spécial), супериори (sире́rieur), сюппюте (supриté), фишант (fichant), фланкан / -нт (flanquant), экилатерал (équilatéral), экстериор (extérieur), эн эшари (еn echarpe), энфиладе (enfilade).

Об активности неизменяемых прилагательных в сочинении Ганнибала говорит сравнение со списками подобных лексем, приводимых в исследованиях и грамматиках для русского языка ХХ в.; список из 51 слова, основанный на данных словаря под ред. Д.Н. Ушакова, приводит А.И. Молотков [1960: 68]; в «Русской грамматике», в параграфе, посвящённом «нулевому» склонению, представлено 69 лексем [Русская грамматика 1980: 556]. Таким образом, количество используемых в сочинениях Ганнибала атрибутивов сопоставимо по объёму употребления данной лексики в русском языке XX века в целом.

Представленные в списке заимствования можно разделить на две группы по их статусу в языке оригинала: это могут быть отдельные слова или предложно-падежные сочетания. Последние используются Ганнибалом единично, например: ежели

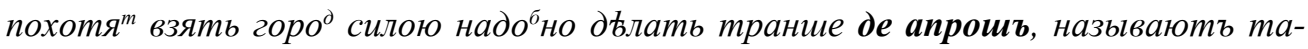

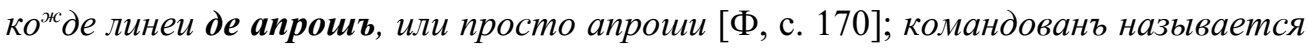
де Өронъ: когда сная вышина или приго ${ }^{p}$ ки смотря ${ }^{m}$ по длине линеи прямси тогда

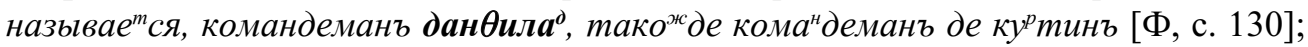
та которая бье $e^{m}$ зsади называется батарея енъ эша ${ }^{p} \boldsymbol{n ъ}$ [Ф, с. 34] и др. Основную же массу атрибутивов составляют заимствования, не включающие в свой состав предлога.

По отдельным лексическим и морфологическим параметрам атрибутивные заимствования применяются А. П. Ганнибалом неоднородно.

В лексическом отношении обращает на себя внимание, что часть галлицизмов снабжена поясняющими глоссами ${ }^{2}$, при этом, что важно отметить, русские соответствия Ганнибал даёт для меньшей части атрибутов - только 25 слов. Единого способа подобных пояснений нет. В большинстве случаев переводящее слово

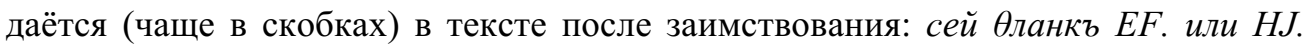
называется Өланкъ дро ${ }^{u}$, \{прямои\} когда буде

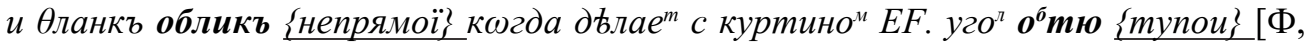
c. 3]; орлионъ LM. котораго называю гль [Ф, с. 3]; также пояснения могут вводиться при помощи дополнительных лексических средств: Фортификовать мъсто, или укреплять чре помощь нъкатара табели называемоі сюппюте, или таблича вычетная (заголовок) [Ф, с. 29]; батареи ентерре сиречъ батареи врытыля [Ф, с. 34]; басти $\omega^{\mu}$ крюз̆ъ сиречъ бастионъ пустои [Ф, с. 35]; стена называется реветементь \{сиречъ одытая\} которая

${ }^{2}$ Ср. активное глоссирование новых заимствований терминологического характера в текстах первой трети XVIII в. [Веселитский 1965; Малышев 2013]. 
вылина сверху глубины рва може был $^{m}$ 4. сажени [Ф, с. 40]. здесь землею рампа

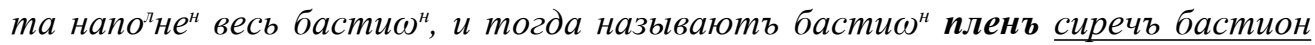
полнои $[\Phi$, с. 72].

Отдельно следует отметить интересный пример, когда Ганнибал затрудняется

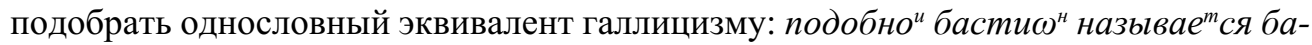
стио $^{\text {н }}$ дӨормъ сиречъ не походит на других низчего [Ф, с. 122] (объясняется значение 'бесформенный'; см. также ниже подобный поясняющий контекст при слове рантран - тют которои входит внутрь).

Неоднократно используемые термины имеют такое пояснение, как правило, только при первом появлении в тексте, и далее используется уже только неизменяемое заимствование - ср. использование термина каре: орлию ${ }^{\mu}$ каре то есть

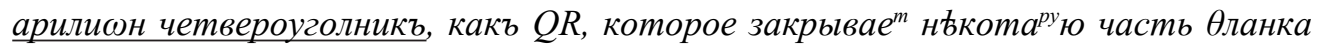
[Ф, с. 3]; линея EL, FL. буду

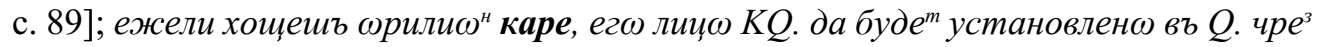
линею прямую тянутую о ${ }^{m}$ точки О. чре средину Өланка бастиюна противнаго [Ф, с. 105]; оная часть стены города нбкогда мьрее $o^{m}$ толсто стень [Ф, с. 205]; а также атрибутива рантран(m): $\mathrm{Mbl} \mathrm{знаемь} \mathrm{так-}$ же чре гешметрию что уго рантранъ, тют которои входит внутрь, и скаже здесь по термина ${ }^{м}$ инженерски $u^{м}$ подобно угш" называе ся уго де тана ${ }^{n}$ [Ф, с. 5];

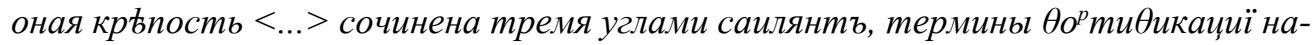
зывають анго ви вь, то есть уго живњ называють англь морть сиречь уго мертвю $^{u}$ [Ф, с. 67]; что бу лутче покры ${ }^{m}$ деми-

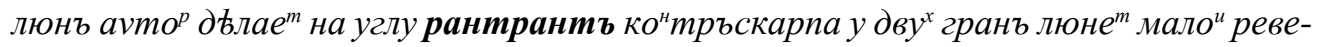
линь [Ф, с. 103]; по нятие земли сочиненно иглами рантра" и селянть [Ф, с. 143];

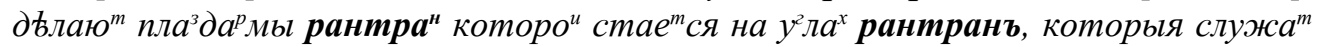
для со ранїя кор пусовъ [Ф, с. 219] $]^{3}$.

Из приведённых выше примеров видно, что заимствованные атрибутивы используются в основном в неизменяемой форме. Только для отдельных лексем в тексте Ганнибала отмечены попытки морфологической адаптации, осуществлённой разными способами. В одних случаях слово склоняется по субстантивному типу. Помимо упомянутого выше исоссель, к ним также относятся слова облик и эксте-

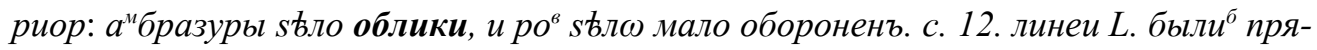
мы и были крьпче и тве же, $и<\ldots>$ оныя лутче поля [Ф, с. 68]; бокъ $A F$, буде лутче укрепленъ, чре $е^{3}$ сию.2ю мани ну нежели

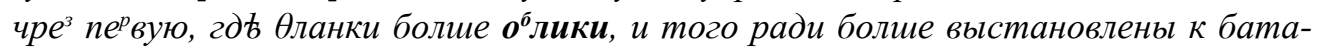

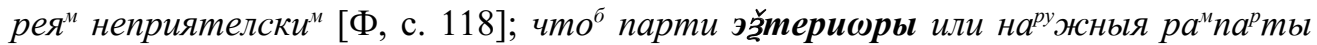
$<\ldots>$ лутче связаны были, то о о кладывають дер номъ [Ф, с. 56]; протяни прямыя линеи пунтированныя которыя называются полигоны эз̌териоры [Ф, с. 148]; двои шанизы дълаются по края ${ }^{м}$ плацуда ${ }^{p}$ ма по линее прямо,$o^{m} к y^{\partial y}$ приближае

${ }^{3}$ Ср. с наблюдением В. В. Веселитского, сделанном на материале сочинений А. Д. Кантемира: «В научных и специальных контекстах предпочтение может отдаваться иноязычным словам как более “терминологичным”» [Веселитский 1965: 54]. 
помалу къ горо ${ }^{\partial y}$, атакова $^{m}$ по длине старань эз̌териюра горада [Ф, с. 174]. Для последнего прилагательного в тексте встретился и контрпример - с неизменяемой формой в позиции косвенного падежа: в равно pa $^{3}$ стоянїи $o^{m}<o>$ количности эз̌̆терио ${ }^{p}[\Phi$, с. 203].

Также параллельное употребление неизменяемой и склоняемой формы наблюдается у тех лексем, адаптация которых достигается добавлением славянского суффикса - адъективного или причастного - к заимствованной основе: можнш себъ упо ${ }^{m}$ ребить для разтворения начала шанецьь, тогда для приближения бли города остане $^{m}$ ся токмо малое ра ${ }^{3}$ стояние земли которая б была анӨиле о города [Ф,

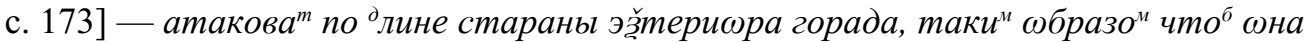
небыла анӨилерована $o^{m}$ города [Ф, с. 174]; а пла с ирърегуляре, какъ $o^{\mu}$ неимъ $e^{m}$

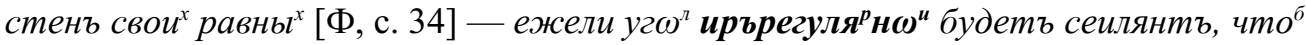

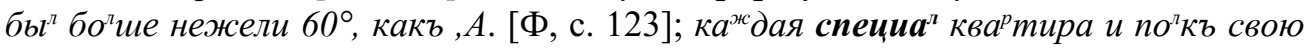
$\kappa в a^{p}$ тиру и гранииу имье $e^{m}$ [Ф, с. 158] - нарисуешь тако специа ную ква тиру особ ливо потомуже мачтапу [Ф, с. 157].

Ещё один морфологический фактор, дающий качественные отличия в функционировании неизменяемых форм в трактатах Ганнибала, напрямую соотносится с классификацией несогласуемых прилагательных современного русского языка, которую предлагает А.А. Зализняк в книге «Русское именное словоизменение». Учёный делит неизменяемые субстантивы на те, за которыми скрывается сразу два омонимичных слова - существительное и прилагательное (типа названий языков хауса, бенгали, коми и т.п., названий некоторых цветов бордо, маренго и некоторые другие слова: соло, модерн, mет-a-mem) и на те, которые могут являться только прилагательными (морзе, хаки, нетто, комильфо и др.) [Зализняк 1967: 98]. Это разделение есть уже в рассматриваемых текстах, что можно видеть из следующих примеров из тома по фортификации (слова кавалиер, авантаж и танал):

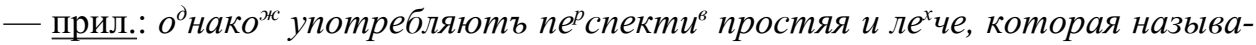
ется перспективъ кавалиеръ тако де и перспективъ милитерь [с. 45];

сущ.: терасы сиречь груды земляныя, болие или менше вышиною по по ребно-

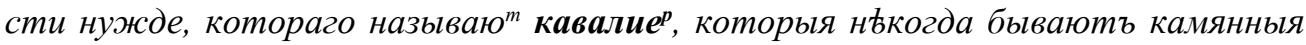
[c. 35];

- прил.: я удивляюся что многия агторы уничтоживаю ${ }^{m}$ вторые Өланки ко-

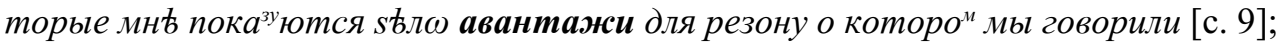

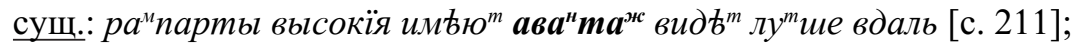

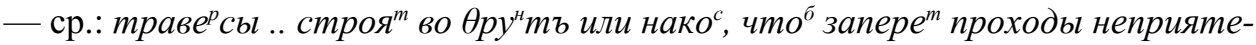

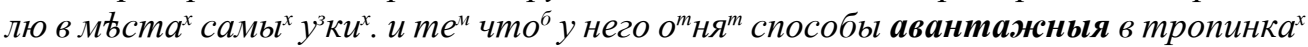
которыя случаются в болота ${ }^{x}[$ с. 71];

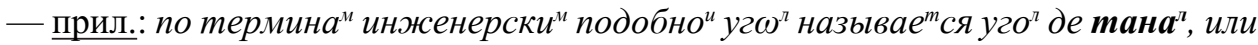
простш тана ${ }^{n}$ [с. 5];

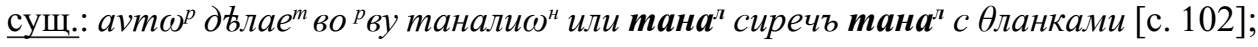




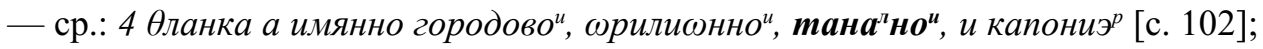
парапе танално о $^{p}$ динарно токмо $15^{c}$ уже, нежели у ${ }^{\partial}$ руги ${ }^{x}$ крьпосте 3 мя фута [c. 218].

По-видимому, такая омонимия была нежелательной, т. к. сопровождается более активным употреблением согласуемой адъективной формы, дополненной русским суффиксом. Редкие случаи морфологической адаптации этой разновидности (с добавлением аффиксов) оказываются в таком случае мотивированными, являясь средством снятия омонимии; в нейтральной же ситуации Ганнибал пользуется инновационными для языка неизменяемыми формами. Это несколько контрастирует с утверждением о том, что «... там, где намечалось более или менее регулярное употребление прилагательного (а не эпизодическое использование слова в речевом контексте билингва), происходило переоформление неадаптированных имен прилагательных с помощью русских суффиксов и специфической системы флексий» [Биржакова и др. 1972: 237].

Кроме того, для двух лексем - облик и каре - в сочинениях Ганнибала встретилась нехарактерная для современного русского языка омонимия прилагательного (адъективные примеры см. выше) и наречия. В трактате по фортификации слово облик встречается в адвербиальном употреблении: <Батарея>

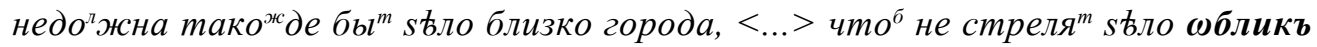

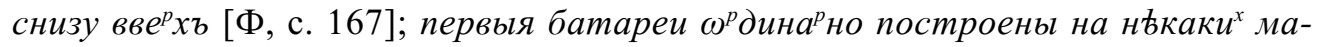

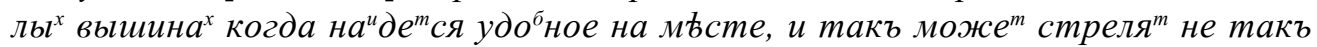
$\boldsymbol{о}^{б}$ ликъ понеже буде $e^{m}$ пониво парапета и рампарта города [Ф, с. 176]; на аналогичное употребление слова каре один пример встретился в томе по геометрии:

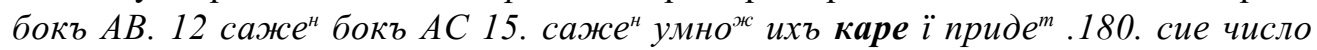
умно ния используется и русифицированная наречная форма этого слова: Для cbl-

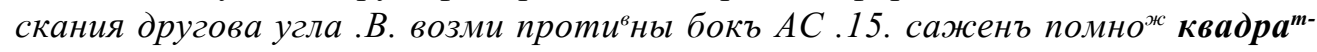
но $\ddot{i}$ приде 225 - что только подчёркивает частеречный статус формы каре). Необычно в подобном употреблении ещё и то, что оригинальные французские лексемы - oblique и carré - в статусе наречия не употребляются, т. е. их адвербиальная позиция в приведённых примерах является инициативой автора русского текста.

Рассмотренные особенности употребления атрибутивной лексики, заимствованной из французского языка, показывают, что выбор неизменяемых форм для передачи терминологии геометрии и особенно фортификации у Ганнибала был вполне осознанным. Автор мог без труда перевести прилагательные на русский язык (ронд - кругльй, плат - плоский, дрои - прямой, крюкс-пустой и т. д.), мог во избежание омонимии образовать склоняемые адъективные формы (иррегуляре > иррегулярный, танал > таналный, авантаж > авантажный), но систематично предпочитал использование неизменяемых прилагательных, а также мог употреблять их в нехарактерной для французского языка функции наречия. Описанный прецедент говорит о том, что потенциально русский язык был готов к появлению новой категории неизменяемых прилагательных уже в первой трети 
XVIII в. Эта возможность не была реализована, по-видимому, в связи с изменением языкового вкуса во второй половине XVIII в., и только в XX в. категория развилась в русском языке.

\section{Источники и словари}

КС XVIII - Картотека «Словаря русского языка XVIII века». ИЛИ РАН (СПб.).

СлРЯ XVIII - Словарь русского языка XVIII века. Вып. 1-22-. СПб., 1984 2019-.

ФРЛ - Полной французской и российской лексикон, с последнего издания лексикона Французской академии на российской язык переведенный Собранием ученых людей. СПб., 1786, т. 1-2.

\section{Литература}

Биржакова Е. Э., Войнова Л. А., Кутина Л. Л. Очерки по исторической лексикологии русского языка XVIII века. Языковые контакты и заимствования. Л., 1972.

Бондаревский Д. В. Категория неизменяемых прилагательных в современном русском языке. Дисс. ... к. филол. н. Ростов-на-Дону, 2000.

Бранднер $A$. Неизменяемые прилагательные иноязычного происхождения в современном русском языке // Sborník prací filozofické fakulty Brněnské Univerzity. A, Řada jazykovědná = Linguistica Brunensia. Vol. 50, iss. A49. 2001. S. 107-118.

Веселитский В. В. Иноязычные слова и их русские эквиваленты у Кантемира // Проблемы современной филологии. Сборник статей к семидесятилетию академика В.В. Виноградова. М., 1965. С. 53-58.

Горбов A.A. Аналитические прилагательные в русском языке // Russian Linguistics. Vol. 40. 2016. Р. 133-152.

Зализняк A. А. Русское именное словоизменение. М., 1967.

Кутина Л.Л. Формирование языка русской науки (Терминология математики, астрономии, географии в первой трети XVIII века). М.; Л., 1964.

Мальшев A. A. Толкования лексики в текстах «Примечаний к Санкт-Петербургским ведомостям» // ACTA LINGUISTICA PETROPOLITANA. Труды Института лингвистических исследований РАН. Т. ІХ. Ч. 2. 2013. С. 393-420.

Молотков А.И. Есть ли в русском языке категория неизменяемых прилагательных? // Вопросы языкознания. 1960. №6. С. 68-73.

Мольков Г.А. Терминология трактатов А. П. Ганнибала «Геометрия практика» и «Фортификация» 1725-1726 гг. // Терминология и знание. Материалы VI Международного симпозиума (Москва, 8-10 июня 2018 г.). М., 2018. С. 179-188.

Русская грамматика. Том 1: Фонетика. Фонология. Ударение. Интонация. Словообразование. Морфология. М., 1980. 


\author{
Georgy A. Mol'kov \\ Institute for Linguistic Studies, RAS \\ (St. Petersburg, Russia) \\ georgiymolkov@gmail.com
}

\title{
BORROWINGS IN THE TREATISES OF A.P. GANNIBAL ON GEOMETRY AND FORTIFICATION (1725-1726): TOWARDS A HISTORY OF INDECLINABLE ADJECTIVES IN RUSSIAN
}

A striking feature of the treatises of A.P. Gannibal (1696-1781) is the large number of Gallicisms in the author's language, primarily in terminology. A significant portion of these borrowings consists of adjectives, the bulk of which are used indeclinably. The article discusses a number of functional features of indeclinable adjectives in Gannibal's language: the presence in some cases of Russian declinable equivalents, attempts at morphological adaptation of some lexemes, cases of homonymy of indeclinable adjectives and nouns. The author prefers morphologically unadapted adjectives to their Russian equivalents and to the formation of declinable adjectives with a borrowed root. Apparently, this feature is associated with the terminological character of their use. In the field of fortification, borrowed terms are represented much more broadly than in the treatise on geometry, because basic geometric terminology already had a tradition of usage in Russian due to the widespread dissemination of geometric knowledge in pre-Petrine Russia.

The language of Gannibal's treatises provides interesting evidence that the Russian language was ready for the emergence of the category of indeclinable adjectives in the first third of the $18^{\text {th }}$ century. This possibility did not come to pass, apparently due to the change in linguistic taste in the second half of the $18^{\text {th }}$ century. Indeclinable adjectives did not develop in Russian until the $20^{\text {th }}$ century.

Keywords: indeclinable adjectives, language of the Petrine era, A.P. Gannibal, fortification terminology, geometric terminology.

\section{References}

Birzhakova E.E., Voynova L.A., Kutina L.L. Ocherki po istoricheskoy leksikologii russkogo yazyka XVIII veka. Yazykovye kontakty i zaimstvovaniya. Leningrad, 1972.

Bondarevskiy D. V. Kategoriya neizmenyaemykh prilagatel'nykh v sovremennom russkom yazyke. Thesis. Rostov-na-Donu, 2000.

Brandner A. Neizmenyaemye prilagatel'nye inoyazychnogo proiskhozhdeniya v sovremennom russkom yazyke. Sborník prací filozofické fakulty Brněnské Univerzity. A, Řada jazykovědná = Linguistica Brunensia. Vol. 50, iss. A49. 2001. S. 107-118.

Gorbov A. A. Analiticheskie prilagatel'nye v russkom yazyke. Russian Linguistics. Vol. 40. 2016. P. 133-152.

Kutina L.L. Formirovanie yazyka russkoy nauki (Terminologiya matematiki, astronomii, geografii v pervoy treti XVIII veka). Moscow; Leningrad, 1964. 
Malyshev A. A. Tolkovaniya leksiki v tekstakh «Primechaniy k Sankt-Peterburgskim vedomostyam». Acta Linguistica Petropolitana. Trudy Instituta lingvisticheskikh issledovaniy RAN. T. IX. Ch. 2. 2013. S. 393-420.

Mol'kov G.A. Terminologiya traktatov A.P. Gannibala «Geometriya praktika» i «Fortifikatsiya» 1725-1726 gg. Terminologiya i znanie. Materialy VI Mezhdunarodnogo simpoziuma (Moskva, 8-10 iyunya 2018 g.). Moscow, 2018. S. 179-188.

Molotkov A. I. Est' li v russkom yazyke kategoriya neizmenyaemykh prilagatel'nykh? Voprosy yazykoznaniya. 1960. №6. S. 68-73.

Russkaya grammatika. Tom 1: Fonetika. Fonologiya. Udarenie. Intonatsiya. Slovoobrazovanie. Morfologiya. Moscow, 1980.

Veselitskiy V.V. Inoyazychnye slova i ikh russkie ekvivalenty u Kantemira. Problemy sovremennoy filologii. Sbornik statey k semidesyatiletiyu akademika V. V. Vinogradova. Moscow, 1965. S. 53-58.

Zaliznyak A. A. Russkoe imennoe slovoizmenenie. Moscow, 1967. 